\title{
Conformational Study of Monomeric 2,3-Butanediols by Matrix-Isolation Infrared Spectroscopy and DFT Calculations
}

\author{
A. J. Lopes Jesus,* Mário T. S. Rosado, Igor Reva, Rui Fausto, M. Ermelinda Eusébio, and \\ J. S. Redinha \\ Departamento de Química, Universidade de Coimbra, 3004-535 Coimbra, Portugal
}

Received: December 13, 2005; In Final Form: February 3, 2006

\begin{abstract}
The FT-IR spectra of two diastereomers of 2,3-butanediol, $(R, S)$ and $(S, S)$, isolated in low-temperature argon and xenon matrixes were studied, allowing the identification of two different conformers for each compound. These conformers were characterized by a \pm gauche arrangement around the $\mathrm{O}-\mathrm{C}-\mathrm{C}-\mathrm{O}$ dihedral angle, thus enabling the establishment of a very weak intramolecular hydrogen bond of the $\mathrm{O} \cdots \mathrm{H}-\mathrm{O}$ type. No other forms of these compounds were identified in matrixes, despite the fact that these four conformers had calculated relative energies from 0 to $5.1 \mathrm{~kJ} \mathrm{~mol}^{-1}$ and were expected to be thermally populated from 50 to $6 \%$ in the gaseous phase of each compound. The nonobservation of additional conformers was explained in terms of low barriers to intramolecular rotation, resulting in the conformational relaxation of the compounds during deposition of the matrixes. The barriers to internal rotation of the $\mathrm{OH}$ groups were computed to be less than $4 \mathrm{~kJ} \mathrm{~mol}^{-1}$ and are easily overcome in matrixes within the family of conformers with the same heavy atom backbone. The barriers for intramolecular rearrangement of the $\mathrm{O}-\mathrm{C}-\mathrm{C}-\mathrm{O}$ dihedral angle in both diastereomers were calculated to range from 20 to $30 \mathrm{~kJ} \mathrm{~mol}^{-1}$. Interconversions between the latter conformers were not observed in matrixes, even after annealing up to $65 \mathrm{~K}$. Energy calculations, barriers, and calculated infrared spectra were carried out at the DFT(B3LYP)/6-311++G** theory. Additional MP2/ $6-311++\mathrm{G}^{* *}$ calculations of energies and vibrational frequencies were performed on the most relevant conformers. Finally, independent estimations of the hydrogen-bond enthalpy in the studied molecules were also obtained based on theoretical structural data and from vibrational frequencies (using well-established empirical correlations). The obtained values for $-\Delta H$ for both diastereomers of 2,3-butanediol amount to ca. $6-8 \mathrm{~kJ} \mathrm{~mol}^{-1}$.
\end{abstract}

\section{Introduction}

Molecular properties for systems bearing two $\mathrm{OH}$ groups connected to adjacent carbon atoms are of special interest. The fragment $\mathrm{R}_{1}-\mathrm{CH}(\mathrm{OH})-\mathrm{CH}(\mathrm{OH})-\mathrm{R}_{2}$ is the main building unit of such important molecules as naturally occurring sugars and polyalcohols. The simplest molecule of the above series is 1,2ethanediol, where $\mathrm{R}_{1}=\mathrm{R}_{2}=\mathrm{H}$. It is well-known that intramolecular hydrogen bonding plays an important role in conformers of 1,2-ethanediol. This molecule has been the subject of numerous studies. (See, for example, the bibliography in ref 1.) If the terminal substituents, $\mathrm{R}_{1}$ and $\mathrm{R}_{2}$, of the $\mathrm{R}_{1}-\mathrm{CH}(\mathrm{OH})-$ $\mathrm{CH}(\mathrm{OH})-\mathrm{R}_{2}$ fragment are different from hydrogen, the molecule then becomes chiral. The simplest chiral representative of the above series is the molecule where $\mathrm{R}_{1}=\mathrm{R}_{2}=\mathrm{CH}_{3}$ (i.e., 2,3-butanediol, $\left.\mathrm{CH}_{3}-\mathrm{CH}(\mathrm{OH})-\mathrm{CH}(\mathrm{OH})-\mathrm{CH}_{3}\right)$. Depending on the configurations of the two chiral carbon atoms, this molecule can exist as three possible stereoisomers: meso form $(R, S),(S, S)$, and $(R, R)$ (Scheme 1). The forms $(S, S)$ and $(R, R)$ are enantiomers. They are spectroscopically, conformationally, and energetically identical, and only one enantiomer can be considered. On the other hand, $(R, S)$ and $(S, S)$ or $(R, R)$ are diastereomers. Having different physical-chemistry properties, both of them should be studied.

The stereoisomers of 2,3-butanediol (2,3-BD) have several industrial applications.,3 They are also used as cryoprotectant

* To whom correspondence should be addressed. E-mail: ajorge@ qui.uc.pt.
SCHEME 1: Newman Projections for the $(R, S)$ and $(S, S)$ Diastereomers of 2,3-BD with the Gauche Arrangement around the $\mathrm{O}-\mathrm{C}-\mathrm{C}-\mathrm{O}$ Dihedral Angle<smiles>CC1C2CC3CC1C(O)C(C3)C2C</smiles>

$(R, S)$<smiles>CC1C2CC3CC1C(O)C(C2C)C3O</smiles>

$(S, S)$ agents. $^{4-9}$ The knowledge of its structure assumes further importance in developing theoretical models for the investigation of the behavior of flexible chiral organic molecules containing polar and nonpolar groups.

Previous infrared spectroscopic studies of this molecule in a dilute solution of inert solvents, ${ }^{10,11}$ vapor phase, ${ }^{11,12}$ and matrix isolation ${ }^{12}$ have shown the presence of a lower-frequency band in the $\mathrm{OH}$-stretching region in addition to the absorption band due to the free $\mathrm{OH}$ (higher-frequency band). This lowerfrequency absorption was assigned to the presence of an intramolecular hydrogen bond between the two hydroxyl groups. ${ }^{1} \mathrm{H}$ NMR and ${ }^{13} \mathrm{C}$ NMR studies ${ }^{13}$ confirm the existence of this interaction in low-polar solvents, whereas in polar solvents, no intramolecular hydrogen bond seems to exist.

The few available computational studies performed on 2,3$\mathrm{BD}$ were carried out using quantum mechanical methods at different levels of theory ${ }^{14-17}$ and molecular mechanics ${ }^{18}$ calculations. These works show that, like in other simple vicinal 
diols, ${ }^{19-21}$ the gauche $\mathrm{O}-\mathrm{C}-\mathrm{C}-\mathrm{O}$ conformations are more stable than those where the $\mathrm{O}-\mathrm{C}-\mathrm{C}-\mathrm{O}$ skeleton assumes a trans conformation. The higher stability of the gauche $\mathrm{O}-\mathrm{C}-$ $\mathrm{C}-\mathrm{O}$ conformations over the trans in vicinal diols has been explained by the formation of an intramolecular $\mathrm{O}-\mathrm{H} \cdots \mathrm{O}$ attractive interaction. Some works describe this interaction as a weak hydrogen bond on the grounds of geometrical and spectroscopic criteria. ${ }^{10-12}$ However, according to electron density topological analysis calculations, there is no evidence for the existence of an intramolecular hydrogen bond. ${ }^{14,16,22,23}$ Because the aim of the present work is not to discuss whether intramolecular hydrogen bonding is present in vicinal diols, we will adopt the definition of hydrogen bond recommended by IUPAC. $^{24}$

A recent study of the molecular structure of butanediol isomers combining DFT calculations with IR spectroscopy studies in carbon tetrachloride solutions was performed in our laboratory. ${ }^{25}$ In that work, it was concluded that the energy differences between the isomers in the gas state are higher than those in the liquid state. Moreover, it was shown that the intramolecular hydrogen bonding plays a determinant role in the conformational behavior of the isolated molecules.

Despite most of the conformational studies on 2,3-BD admitting the importance of intramolecular hydrogen bonding, experimentally, it is very difficult to distinguish a particular conformer, namely, those able to form an intramolecular hydrogen bond. This difficulty arises from the fact that the spectral signatures of the conformers of a similar type are very similar, and the number of possible conformers is large. Thus, isolation of monomers of the studied molecules in cryogenic inert matrixes gives a unique possibility of characterization of their particular conformers. Contrary to the neat condensed phases, the bands in the spectra of matrix-isolated species are very narrow (of the order of a few $\mathrm{cm}^{-1}$ ), and contrary to the gaseous phase, the vibrational bands are not accompanied by rotational structure, thus allowing identification of the signals being apart from each other only by a few $\mathrm{cm}^{-1}$. This peculiarity of the matrix isolation spectra gives also possibility to compare directly experimental and theoretically calculated spectra of monomers, allowing their reliable identification.

The aim of this work is to have a deeper insight into the structure of the monomeric forms of $(R, S)-2,3-\mathrm{BD}$ and $(S, S)$ 2,3-BD, by the combination of matrix-isolation infrared spectroscopy and high level theoretical calculations.

\section{Experimental Section}

Commercial $(S, S)-2,3-\mathrm{BD}$ (Aldrich, $>99 \%)$ and $(R, S)-2,3-$ BD (Aldrich, $>99 \%$ ) were used in the present study. The purity of the compounds was checked by GLC and the following values were obtained: $99.3 \pm 0.1 \%$ for $(R, S)-2,3-\mathrm{BD}$ and $99.4 \pm 0.2 \%$ for $(S, S)-2,3$-BD. Due to their high hygroscopicity, they were transferred from the factory packing into the effusive cell in a glovebox previously purged with dry nitrogen. An effusive Knudsen cell ${ }^{26}$ was equipped with a SS-4BMRG (NUPRO) needle valve and permitted to avoid the contact of the sample compartment with atmosphere before experiments. Prior to experiment, the cell was connected to the vacuum system of the cryostat, and the compound was additionally purified from dissolved gases by pumping. The cell has two thermostatable parts: the valve nozzle and the sample compartment, both separately temperature controlled. During deposition, the sample compartment was cooled to $0{ }^{\circ} \mathrm{C}$ by immersing the ampule with the compound into a bath with melting water-ice mixture. This allowed for reducing the saturated vapor pressure over the compound and improving the metering function of the valve. The valve nozzle was kept at $295 \mathrm{~K}$, and this temperature defined the equilibrium ratio of butanediol conformers in the vapor before deposition.

The deposition rate of the compound was chosen low enough to ensure that the species trapped in matrixes were mainly monomers. A CsI window was used as an optical substrate for the matrixes. Its temperature was stabilized and measured directly at the sample holder by a silicon diode sensor connected to a digital controller (Scientific Instruments, Model 9650-1), with an accuracy of $0.1 \mathrm{~K}$.

A glass vacuum system and standard manometric procedures were applied to deposit matrix gases (argon N60 and xenon N45, supplied by Air Liquide), which were used without further purification. The low-temperature equipment was based on a closed-cycle helium refrigerator (APD Cryogenics) with a DE202A expander. Infrared spectra in argon and xenon matrixes at 10 and $20 \mathrm{~K}$, respectively, were registered with a resolution of $0.5 \mathrm{~cm}^{-1}$, in the range $4000-400 \mathrm{~cm}^{-1}$, using a Mattson (Infinity 60AR Series) Fourier transform infrared spectrometer equipped with a deuterated triglycine sulfate (DTGS) detector and a $\mathrm{KBr}$ beam splitter. Modifications of the sample compartment of the spectrometer were made to couple it with the cryostat head and allow purging of the instrument by a stream of dry nitrogen to remove carbon dioxide and water vapors.

\section{Computational Methods}

2,3-Butanediols can exist in a great variety of conformational structures. For both diastereomers of 2,3-BD, the backbone arrangement is defined by only one dihedral angle $(\mathrm{O}-\mathrm{C}-\mathrm{C}-$ $\mathrm{O})$, whereas two additional dihedral angles $(\mathrm{H}-\mathrm{O}-\mathrm{C}-\mathrm{C})$ define orientations of the two hydroxyl groups. Considering three conformational possibilities: trans (ca. $180^{\circ}$ ), +gauche (ca. $+60^{\circ}$ ), and - gauche $\left(\mathrm{ca} .-60^{\circ}\right.$ ) for each relevant dihedral angle, one can predict the number of possible conformers. Thus, three dihedral angles, with 3 -fold configuration each, lead to $3^{3}=$ 27 possible conformers. However, symmetry relationships reduce this number to 15 and 18 conformations for $(R, S)-2,3$ $\mathrm{BD}$ and $(S, S)-2,3-\mathrm{BD}$, respectively. The relatively moderate number of possible minima on the potential energy surface allows for exploring all of them by high level quantummechanical methods.

All possible conformations of the two molecules were fully optimized at the DFT(B3LYP)/6-311++G** level of approximation. ${ }^{27-29}$ The lower energy conformers predicted by the DFT method with relative energies up to $10 \mathrm{~kJ} \mathrm{~mol}^{-1}$ above the global minima were also optimized at the MP2/6-311++G** level. ${ }^{30-32}$ All calculations were performed using the GAUSSIAN 98 program package, ${ }^{33}$ with explicit symmetry when applicable.

After the geometry optimizations, the harmonic vibrational frequencies calculation, at the same level of theory, was carried out to characterize the nature of each stationary point. The calculated IR spectra were also used to assist in the interpretation of the experimental spectra and to account for the zero-point vibrational energy (ZPVE) contribution. Sets of internal coordinates were defined and the Cartesian force constants were transformed to the internal coordinates space, allowing ordinary normal-coordinate analysis to be performed as described by Schachtschneider. ${ }^{34}$ The theoretical normal modes were characterized by analysis of the potential energy distribution (PED) matrix resulting from these calculations.

\section{Results and Discussion}

4.1. Conformers of 2,3-Butanediols. DFT Computational Studies. The conformers of both 2,3-BD diastereomers are 
TABLE 1: Relative Energies $\left(\Delta E_{0}\right.$, in $\left.\mathrm{kJ} \mathrm{mol}^{-1}\right)$, Equilibrium Boltzmann Populations (in \%) at $295 \mathrm{~K}$, Dipole Moments $(\mu$, in Debye), and Hydrogen-Bonding Parameters (Angles in Degrees and Distances in $\AA$ ) Calculated for the Conformers of the Two Diastereomers of 2,3-BD

\begin{tabular}{|c|c|c|c|c|c|c|c|c|c|}
\hline \multirow[b]{2}{*}{ conformer } & \multirow[b]{2}{*}{ label } & \multicolumn{2}{|c|}{$\Delta E_{\mathrm{o}}{ }^{a}$} & \multirow[b]{2}{*}{ symmetry } & \multirow[b]{2}{*}{ pop. ${ }^{b}$} & \multirow[b]{2}{*}{$\mu^{c}$} & \multicolumn{3}{|c|}{ hydrogen-bonding parameters ${ }^{c, d}$} \\
\hline & & B3LYP & MP2 & & & & $\mathrm{O}^{\mathrm{D}}-\mathrm{H}$ & $\mathrm{O}^{\mathrm{A}} \cdots \mathrm{H}$ & $\mathrm{O}^{\mathrm{D}}-\mathrm{H} \cdot \cdots \mathrm{O}^{\mathrm{A}}$ \\
\hline \multicolumn{10}{|c|}{$(R, S)-2,3-\mathrm{BD}$} \\
\hline I & $\mathrm{tGg}^{\prime}$ & 0.00 & 0.00 & $C_{1}$ & 45.1 & 2.53 & 0.965 & 2.29 & 108.7 \\
\hline II & $\mathrm{gGg}^{\prime}$ & 1.85 & 2.07 & $C_{1}$ & 21.2 & 2.37 & 0.966 & 2.31 & 111.6 \\
\hline III & $\mathrm{tG}^{\prime} \mathrm{g}$ & 2.58 & 2.80 & $C_{1}$ & 15.8 & 2.69 & 0.966 & 2.29 & 109.1 \\
\hline IV & $\mathrm{g}^{\prime} \mathrm{G}^{\prime} \mathrm{g}$ & 4.52 & 5.61 & $C_{1}$ & 7.2 & 2.85 & 0.967 & 2.28 & 112.7 \\
\hline $\mathrm{V}$ & $\mathrm{tTt}$ & 5.22 & 6.16 & $C_{i}$ & 2.7 & 0.00 & - & - & - \\
\hline VI & $\mathrm{tTg}$ & 6.29 & 8.09 & $C_{1}$ & 3.5 & 1.87 & - & - & - \\
\hline VII & $\mathrm{g}^{\prime} \mathrm{Tg}$ & 7.61 & 10.18 & $C_{i}$ & 1.0 & 0.00 & - & - & - \\
\hline VIII & $\mathrm{tTg}^{\prime}$ & 7.92 & 9.19 & $C_{1}$ & 1.8 & 2.26 & - & - & - \\
\hline IX & $\mathrm{gTg}^{\prime}$ & 8.52 & 9.80 & $C_{i}$ & 0.7 & 0.00 & - & - & - \\
\hline $\mathrm{X}$ & gTg & 9.58 & 11.44 & $C_{1}$ & 0.9 & 2.45 & - & - & - \\
\hline XI & $\mathrm{gGt}$ & 15.65 & - & $C_{1}$ & 0.1 & 3.36 & - & - & - \\
\hline XII & $\mathrm{tGg}$ & 17.68 & - & $C_{1}$ & $<0.1$ & 3.38 & - & - & - \\
\hline \multicolumn{10}{|c|}{$(S, S)-2,3-\mathrm{BD}$} \\
\hline I & $\mathrm{tGg}^{\prime}$ & 0.00 & 0.00 & $C_{1}$ & 50.3 & 2.80 & 0.966 & 2.18 & 111.9 \\
\hline II & $\mathrm{gGg}^{\prime}$ & 1.67 & 2.07 & $C_{1}$ & 25.5 & 2.79 & 0.966 & 2.18 & 114.8 \\
\hline III & $\mathrm{tG}^{\prime} \mathrm{g}$ & 3.13 & 2.86 & $C_{1}$ & 14.1 & 2.53 & 0.966 & 2.31 & 108.0 \\
\hline IV & $g^{\prime} G^{\prime} g$ & 5.10 & 5.50 & $C_{1}$ & 6.3 & 2.54 & 0.967 & 2.30 & 112.0 \\
\hline $\mathrm{V}$ & $\mathrm{gG}^{\prime} \mathrm{g}$ & 5.81 & $6.12^{e}$ & $C_{2}$ & 2.4 & 0.44 & - & - & - \\
\hline VI & $\mathrm{tTt}^{\circ}$ & 11.13 & 10.58 & $C_{2}$ & 0.3 & 0.32 & - & - & - \\
\hline VII & $\mathrm{tTg}^{\prime}$ & 11.80 & - & $C_{1}$ & 0.4 & 2.05 & - & - & - \\
\hline VIII & $\mathrm{g}^{\prime} \mathrm{Tg}^{\prime}$ & 12.87 & - & $C_{2}$ & 0.1 & 2.02 & - & - & - \\
\hline IX & $\mathrm{g}^{\prime} \mathrm{Tg}$ & 13.43 & - & $C_{1}$ & 0.2 & 0.40 & - & - & - \\
\hline$X$ & $\mathrm{~g}^{\prime} \mathrm{G}^{\prime} \mathrm{g}^{\prime}$ & 13.53 & - & $C_{2}$ & 0.1 & 1.93 & - & - & - \\
\hline XI & $\mathrm{tTg}$ & 13.60 & - & $C_{1}$ & 0.2 & 2.21 & - & - & - \\
\hline XII & $t G^{\prime} t$ & 15.00 & - & $C_{2}$ & 0.1 & 1.58 & - & - & - \\
\hline XIII & gTg & 16.76 & - & $C_{2}$ & $<0.1$ & 2.87 & - & - & - \\
\hline XIV & $g^{\prime} G^{\prime} t$ & 17.60 & - & $C_{1}$ & $<0.1$ & 3.35 & - & - & - \\
\hline $\mathrm{TS}^{e}$ & $\mathrm{~g}^{\prime} \mathrm{Gg}^{\prime}$ & 3.60 & 4.21 & $C_{2}$ & - & 0.66 & & & \\
\hline $\mathrm{TS}^{e}$ & $\mathrm{gGg}$ & 13.22 & - & $C_{2}$ & - & 1.77 & & & \\
\hline
\end{tabular}

${ }^{a} E_{\mathrm{o}}=E_{\text {elec }}+$ ZPVE. B3LYP/6-311++G**; $E_{\mathrm{o}}\left(\mathrm{tGg}^{\prime}\right)=-308.8526569 E_{\mathrm{h}}$ for $(R, S)-2,3-\mathrm{BD} ; E_{\mathrm{o}}\left(\mathrm{tGg}^{\prime}\right)=-308.8535425 E_{\mathrm{h}}$ for $(S, S)-2,3-\mathrm{BD}$. $\mathrm{MP} 2 / 6-311++\mathrm{G}^{* *} ; E_{\mathrm{o}}\left(\mathrm{tGg}^{\prime}\right)=-307.9827147 E_{\mathrm{h}}$ for $(R, S)-2,3-\mathrm{BD} ; E_{\mathrm{o}}\left(\mathrm{tGg}^{\prime}\right)=-307.9832621 E_{\mathrm{h}}$ for $(S, S)-2,3-\mathrm{BD}{ }^{b}$ Populations were calculated using DFT energies. A degeneracy factor of 2 was used for the conformers belonging to the $C_{1}$ point group and degeneracy factor of 1 for the conformers belonging to the $C_{i}$ and $C_{2}$ point groups. ${ }^{c}$ Obtained by B3LYP/6-311++G**. ${ }^{d} \mathrm{O}^{\mathrm{D}}=$ donor oxygen atom; $\mathrm{O}^{\mathrm{A}}=$ acceptor oxygen atom. ${ }^{e} \mathrm{TS}=$ transition state (first-order saddle point).

identified by three letters. The letters used are $\mathrm{g}$ or $\mathrm{G}$ (+gauche), $\mathrm{g}^{\prime}$ or $\mathrm{G}^{\prime}$ (-gauche), and t or $\mathrm{T}$ (trans). The capital letters refer to the heavy atom backbone structure, whereas the lower-case ones describe the rotations of the $\mathrm{OH}$ groups. The middle capital letter refers to the $\mathrm{O}-\mathrm{C}-\mathrm{C}-\mathrm{O}$ dihedral angle, whereas the first and third lower-case letters specify the $\mathrm{H}(2)-\mathrm{O}(2)-\mathrm{C}(2)-\mathrm{C}(3)$ and $\mathrm{C}(2)-\mathrm{C}(3)-\mathrm{O}(3)-\mathrm{H}(3)$ dihedral angles orientation, respectively.

The values of the calculated relative energies $\left(\Delta E_{\mathrm{o}}\right)$, represented as the sum of electronic and the zero-point vibrational energies $\left(E_{\mathrm{o}}=E_{\text {elec }}+\mathrm{ZPVE}\right)$, relative populations, dipole moments, and other relevant structural parameters of the conformers are displayed in Table 1. The conformers' populations at $295 \mathrm{~K}$ (nozzle temperature) were calculated by the Boltzmann distribution taking into account relative DFT energies and the degeneracy degree of each conformer.

As can be seen from Table 1, for both molecules, the energy differences between the most relevant conformers are very close in DFT (B3LYP) and MP2 methods. Because the DFT method is computationally less expensive, it was chosen to explore all the conformational space of the two molecules. Unless otherwise stated, all the following discussion is based on the results obtained by DFT.

From the 15 different possible conformations for $(R, S)-2,3-$ $\mathrm{BD}$, only 12 appeared to be minima, as gGg converged to $\mathrm{g}^{\prime} \mathrm{Gg}$ and both $\mathrm{g}^{\prime} \mathrm{Gg}^{\prime}$ and $\mathrm{tGt}$ converged to $\mathrm{tGg}^{\prime}$. Regarding $(S, S)$ 2,3-BD, from the 18 candidates to minima on the potential energy surface, only 14 are true minima, as is displayed in
Table 1 . The g' $\mathrm{Gg}^{\prime}$ structure (with explicit $C_{2}$ symmetry) was characterized as a first-order saddle point having one imaginary vibrational frequency, and tGt (also with explicit $C_{2}$ symmetry) converged to $\mathrm{g}^{\prime} \mathrm{Gg}^{\prime}$. Without restriction of symmetry structures, $\mathrm{g}^{\prime} \mathrm{Gg}^{\prime}$ and $\mathrm{tGg}$ converged to the most stable form $\mathrm{tGg}^{\prime}$, whereas gGg converged to g' $\mathrm{gg}^{\prime}$.

The conformational stability of both diastereomers of 2,3$\mathrm{BD}$ is determined essentially by the $\mathrm{O}-\mathrm{C}-\mathrm{C}-\mathrm{O}$ dihedral angle. The four most stable conformers of both compounds, which are shown in Figure 1, have this dihedral angle in the $\mathrm{G}$ or $\mathrm{G}^{\prime}$ configuration. The higher stability of the gauche $\mathrm{O}-\mathrm{C}-\mathrm{C}-\mathrm{O}$ axis over the trans configuration may be due to the formation of an intramolecular hydrogen bond and/or to the so-called "gauche effect". ${ }^{35-37}$ The four conformers, at $295 \mathrm{~K}$, comprise ca. 89 and $96 \%$ of the gas phase conformational equilibrium mixture of $(R, S)-2,3-\mathrm{BD}$ and $(S, S)-2,3-\mathrm{BD}$, respectively (Table 1).

From the data presented in Table 1, one can see that the $\mathrm{O}^{\mathrm{A}} \cdot \cdot \mathrm{H}$ distance $\left(\mathrm{O}^{\mathrm{A}}=\right.$ acceptor oxygen $)$ is within the criteria commonly accepted for the existence of an intramolecular hydrogen bond. ${ }^{38,39}$ Nevertheless, the great deviation of the $\mathrm{O}^{\mathrm{D}}-$ $\mathrm{H} \cdots \mathrm{O}^{\mathrm{A}}$ angle $\left(\mathrm{O}^{\mathrm{D}}=\right.$ donor oxygen $)$ from the most favorable direction $\left(180^{\circ}\right)$ turns the bond into a weak one. An identical conclusion is drawn from the small shortening of the $\mathrm{O}^{\mathrm{D}}-\mathrm{H}$ distance relative to that observed for the free $\mathrm{OH}$ group (ca. $0.962 \AA$ ). The Mülliken atomic charges of the hydrogen atoms bonded to $\mathrm{O}^{\mathrm{D}}$ are generally more positive than those bonded to $\mathrm{O}^{\mathrm{A}}$, which reinforces the existence of the hydrogen bond. As 
(A)
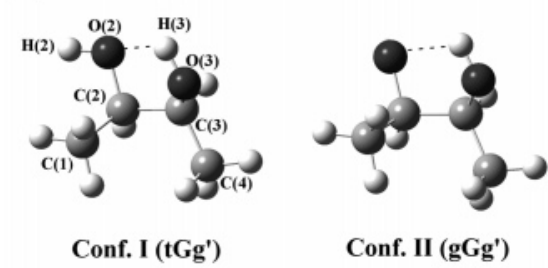

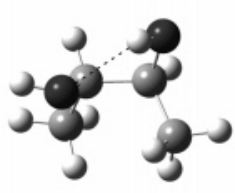

Conf. III (tG'g)

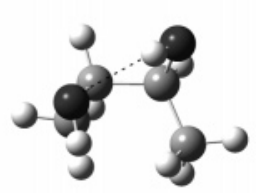

Conf. IV (g'G'g)

(B)

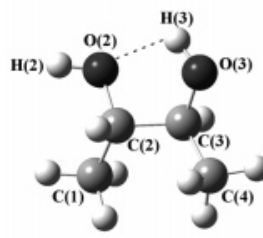

Conf. I (tGg')

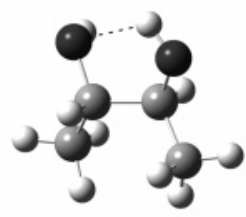

Conf. II (gGg')

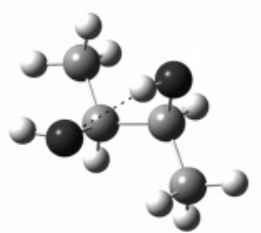

Conf. III (tG'g)

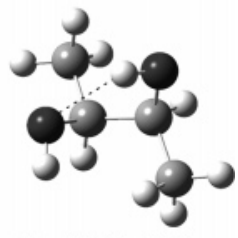

Conf. IV (g'G'g)

Figure 1. B3LYP/6-311++G** optimized geometries of the most relevant conformers of: $(\mathrm{A})(R, S)-2,3-\mathrm{BD}$ and $(\mathrm{B})(S, S)-2,3-\mathrm{BD}$. Atom numbering scheme is given in the lowest energy conformers.

will be shown later in this paper, spectroscopy confirms the existence of a weak intramolecular hydrogen bond that has to be taken into account in the conformational analysis of both diastereomers of 2,3-BD.

Another contribution to the energy of the conformers stabilized by intramolecular hydrogen bonding comes from the orientation of the $\mathrm{OH}$ acceptor group. Indeed, this group is preferentially trans relative to the adjacent $\mathrm{OC}-\mathrm{CO}$ bond, which is in agreement with the theoretical predictions reported for more simple vicinal diols as 1,2-ethanediol ${ }^{1,21,40,41}$ and 1,2-propanediol. ${ }^{20,42}$ From the comparison between two pairs of conformers (I and II) and (III and IV) for the two diastereomers (see Figure 1), the energy difference between $\mathrm{OH}$ trans and $\mathrm{OH}$ gauche can be estimated as being ca. $2 \mathrm{~kJ} \mathrm{~mol}^{-1}$ (see Table 1). This is a low-energy difference, and the question can arise as to if it can be trusted. The coincidence of the relative energy values obtained by two different methods (DFT and MP2) gives a positive answer. This conclusion is further reinforced by experiment, as will be shown below.

The remaining conformers presented in Table 1 have no intramolecular hydrogen bond. A rough estimation of the stabilizing effect due to the formation of the intramolecular hydrogen bond can be made by comparing the energy of the conformers with similar structures with and without a hydrogen bond. For example, conformers I and VIII of $(R, S)$-2,3-BD differ from one another only in the $\mathrm{O}-\mathrm{C}-\mathrm{C}-\mathrm{O}$ dihedral angle, which is $\mathbf{G}$ in the former and $\mathbf{T}$ in the latter. A hydrogen bond is present in conformer I and not in conformer VIII. In choosing the conformers to be compared, it is necessary to take into consideration that no additional strong intramolecular interaction should be present in any of them [for example, the repulsive interaction between the lone electron pairs of $\mathrm{O}(2)$ and $\mathrm{O}(3)]$. Using this procedure and averaging the results over all relevant pairs of conformers for the two stereoisomers, the hydrogenbond energy in 2,3-BD could be estimated as being ca. $8 \mathrm{~kJ}$ $\mathrm{mol}^{-1}$.

A special comment should be made about the symmetries of molecules. The highest possible symmetry for the $(R, S)$ compound is the $C_{i}$. The $(R, S)-2,3-\mathrm{BD}$ can adopt a symmetrical form only when the heavy atom backbone assumes the trans orientation around the $\mathrm{O}-\mathrm{C}-\mathrm{C}-\mathrm{O}$ dihedral angle. In such an orientation, three possible combinations of the $\mathrm{H}-\mathrm{O}-\mathrm{C}-\mathrm{C}$ dihedral angles are possible (see conformers V, VII, and IX in Table 1). None of these orientations exhibits an intramolecular hydrogen bond. In accordance with this fact, all conformers belonging to the $C_{i}$ point group are less stable by 5 or more kJ $\mathrm{mol}^{-1}$ with respect to the most stable form. The forms of the $C_{i}$ symmetry contribute to the conformational equilibrium with the weighting factor of unity. The conformers belonging to the $C_{1}$ point group have their degeneracies equal to two. That is why the four most stable forms of the $(R, S)$ compound are responsible for almost $90 \%$ of the equilibrium conformational mixture at $295 \mathrm{~K}$.

The highest possible symmetry of the $(S, S)$ compound is the $C_{2}$. In this case, a formally symmetrical geometry can be constructed with any orientation of the $\mathrm{O}-\mathrm{C}-\mathrm{C}-\mathrm{O}$ dihedral angle, either trans or \pm gauche. The only formal requirement for a symmetrical geometry is that the two $\mathrm{H}-\mathrm{O}-\mathrm{C}-\mathrm{C}$ dihedral angles are equal. With the three possible orientations of the heavy atom backbone and three possible orientations of the two hydroxyl groups, the total number of symmetrical geometries increases to nine. Six of them are minima on the potential energy surface (see Table 1), and two of them $\left(\mathrm{g}^{\prime} \mathrm{Gg}^{\prime}\right.$ and $\mathrm{gGg}$ ) are the first-order saddle points. The ninth symmetrical structure (tGt) converged, after optimization, to $\mathrm{g}^{\prime} \mathrm{Gg}^{\prime}$, as mentioned above. It is important to note that the formation of an intramolecular hydrogen bond in the $(S, S)$ compound renders two nonequal $\mathrm{OH}$ groups, thus reducing the molecular symmetry to $C_{1}$. As in the case of the $(R, S)$ compound, this means that the four most stable conformers, all belonging to the $C_{1}$ group (see Table 1), contribute to the conformational equilibrium with a weighting factor of 2 and are then responsible for more than $96 \%$ of the conformational population at $295 \mathrm{~K}$.

4.2. Barriers to Intramolecular Rotation. At low temperature, a matrix is a nonequilibrium system. It is often assumed that the conformational composition of the studied molecules in a matrix corresponds to the equilibrium Boltzmann distribution of conformers in the gaseous phase prior to deposition. This assumption is true when the barriers to interconformational changes are high enough and the temperature of the matrix substrate is very low. However, for the species with intrinsically low barriers for intramolecular rotation, these barriers can be overcome at low temperatures, and the relaxation of higherenergy conformers into lower-energy species may occur. This phenomenon is known as conformational cooling.

In 1984, Barnes pointed out that the matrix temperature at which conformational cooling occurs can be related with the barrier to intramolecular rotation..$^{43}$ Recently, we have demonstrated that this temperature depends not only on the barrier of internal rotation but also on the nature of matrix gas. The most 


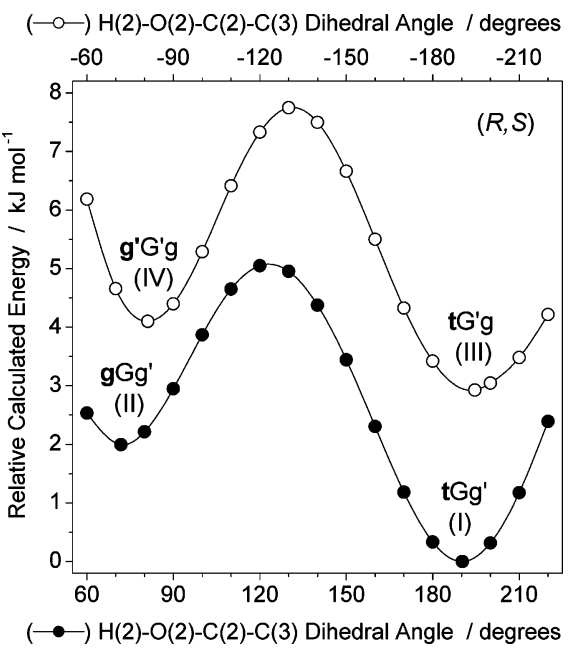

Figure 2. Potential energy profiles for intramolecular rotation of the free $\mathrm{OH}$ group (hydrogen-bond acceptor) in two families of $(R, S)-2,3$ $\mathrm{BD}$, with $\mathrm{G}$ (lower curve) and $\mathrm{G}^{\prime}$ (upper curve) arrangement around the $\mathrm{O}-\mathrm{C}-\mathrm{C}-\mathrm{O}$ dihedral angle. For each point, the $\mathrm{H}(2)-\mathrm{O}(2)-\mathrm{C}(2)-$ $\mathrm{C}(3)$ dihedral angle was kept fixed, whereas all the other internal coordinates were optimized at the B3LYP/6-311++ $\mathrm{G}^{* *}$ level of theory. The dihedral angles corresponding to the reaction coordinates are shown by bold letters in conformer names. Note that abscissas for the two potential curves have the same absolute value and different signs. The zero-level is equal to $-308.9936139 E_{\mathrm{h}}$ and corresponds to the electronic energy of the most stable conformer $\left(\mathrm{tGg}^{\prime}\right)$ without the zeropoint vibrational energy correction.

facile conformational cooling occurs in xenon, whereas in krypton and argon the relaxant properties of the matrix progressively decrease at the same temperature with the same compound studied. ${ }^{44}$ Also, in different compounds with the same barrier to intramolecular rotation, conformational cooling occurs much easier for the smaller groups undergoing intramolecular rearrangement. ${ }^{45}$ With this idea in mind, the barriers to intramolecular rotation in the studied butanediols have been calculated in this work.

The barriers to the internal rotation of the $\mathrm{OH}$ groups in $(R, S)$ and in $(S, S)$-2,3-BD are presented in Figures 2 and 3, respectively. The four calculated barriers do not exceed $3.6 \mathrm{~kJ} \mathrm{~mol}^{-1}$ in the direction of the expected conformational relaxation, i.e. from higher to lower energy minima. In the cases presented in Figures 2 and 3, the group undergoing intramolecular rearrangement is a hydroxyl group, i.e. the group of an extremely small size. This means that for eventual successful trapping in a matrix of the higher energy forms $\mathrm{g}^{\prime} \mathrm{G}^{\prime} \mathrm{g}$ and $\mathrm{gGg}^{\prime}$ (for both compounds), it is necessary to use argon as the matrix gas and use the lowest possible temperature of the optical substrate during deposition of the sample. Such experimental conditions were kept, and the results are presented in the following section.

A special case of the barrier of intramolecular rotation relates to the $\mathrm{g}^{\prime} \mathrm{Gg}^{\prime}$ conformer in the $(S, S)$ compound. This form, when optimized with the explicit $C_{2}$ symmetry, exhibits one imaginary vibrational frequency. An important geometrical parameter in this case is $\boldsymbol{g}^{\prime}$, the value of the two $\mathrm{H}-\mathrm{O}-\mathrm{C}-\mathrm{C}$ dihedral angles. In $\mathrm{g}^{\prime} \mathrm{Gg}^{\prime}$, it is equal to $\mathrm{ca}$. $-76.1^{\circ}$. Visualization of the corresponding vibrational mode corresponds to the concerted movement of the two $\mathrm{OH}$ groups around the $\mathrm{C}-\mathrm{O}$ bonds toward the global energy minimum geometry, $\mathrm{tGg}^{\prime}$. Keeping the overall $C_{2}$ symmetry prevents the molecule from relaxing to a lowerenergy nonsymmetrical geometry. If molecular symmetry is lifted, then the $\mathrm{g}^{\prime} \mathrm{Gg}^{\prime}$ form converges to the global energy minimum, $\mathrm{tGg}^{\prime}$. In $\mathrm{tGg}^{\prime}$, one of the $\mathrm{OH}$ groups remains in the $\mathrm{g}^{\prime}$ position, but the corresponding $\mathrm{H}-\mathrm{O}-\mathrm{C}-\mathrm{C}$ angle assumes the value of $-46.4^{\circ}$ whereas the other adopts the trans

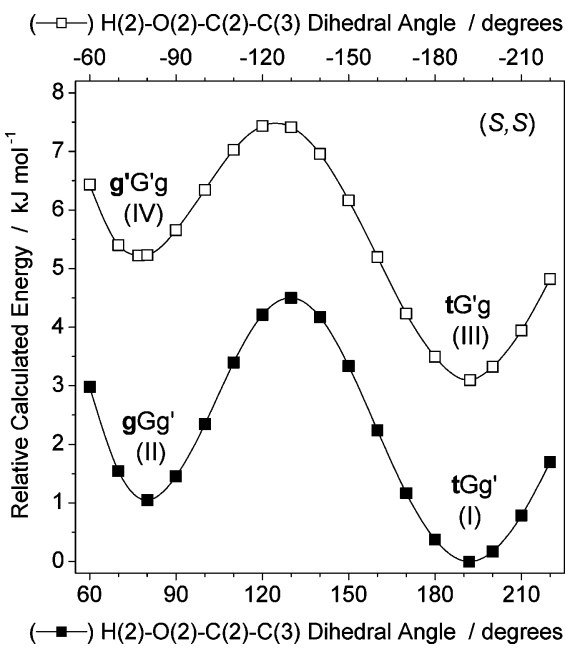

Figure 3. Potential energy profiles for intramolecular rotation of the free $\mathrm{OH}$ group (hydrogen-bond acceptor) in two families of $(S, S)-2,3$ $\mathrm{BD}$, with $\mathrm{G}$ (lower curve) and $\mathrm{G}^{\prime}$ (upper curve) arrangement around the $\mathrm{O}-\mathrm{C}-\mathrm{C}-\mathrm{O}$ dihedral angle. For each point, the $\mathrm{H}(2)-\mathrm{O}(2)-\mathrm{C}(2)-$ $\mathrm{C}(3)$ dihedral angle was kept fixed, whereas all the other internal coordinates were optimized at the B3LYP/6-311++ $\mathrm{G}^{* *}$ level of theory. The dihedral angles corresponding to the reaction coordinates are shown by bold letters in conformer names. Note that abscissas for the two potential curves have the same absolute value and different signs. The zero-level is equal to $-308.9943005 E_{\mathrm{h}}$ and corresponds to the electronic energy of the most stable conformer $\left(\mathrm{tGg}^{\prime}\right)$ without the zeropoint vibrational energy correction.

orientation $\left(-168.2^{\circ}\right)$, characteristic of $\mathrm{tGg}^{\prime}$. The importance of this case is that the energy of the $\mathrm{g}^{\prime} \mathrm{Gg}^{\prime}$ (a transition state) is only $3.6 \mathrm{~kJ} \mathrm{~mol}^{-1}$ with respect to the global minimum. This means that even if the two $\mathrm{OH}$ groups are simultaneously involved into the intramolecular rotation, the energy necessary for such rearrangement is extremely low and does not exceed the energy of barriers presented in Figures 1 and 2. In the $(R, S)$ compound, by its nature, it is impossible to impose a molecular symmetry onto a conformation like $\mathrm{g}^{\prime} \mathrm{Gg}^{\prime}$, and as was mentioned above, such conformation converges upon optimization to the global energy minimum, $\mathrm{tGg}^{\prime}$.

4.3. Interpretation of the Vibrational Spectra. The infrared spectra of $(R, S)$ - and $(S, S)$-2,3-butanediols isolated in argon matrixes at $10 \mathrm{~K}$ (the lowest possible temperature) are presented in Figures 3 and 4, respectively. These figures also include the theoretical spectra (B3LYP/6-311++ $\mathrm{G}^{* *}$ ) of the four most stable conformers of each isomer in the gas phase and the calculated global spectra (population weighted theoretical spectra). The calculated frequencies were scaled by two correction factors: 0.948 for the $\mathrm{OH}$-stretching region and 0.978 for the region below $1500 \mathrm{~cm}^{-1}$. The first scaling factor was obtained by fitting the calculated frequencies to the experimental frequencies in the $\mathrm{OH}$-stretching region, whereas the second was taken from literature. ${ }^{46}$ These corrections account for the neglect of the anharmonic effects, incomplete treatment of the electron correlation, and basis set limitations. ${ }^{47}$ The calculated IR intensities of the spectra of individual conformers were also scaled by their respective abundances, as in detail explained below. The assignment of the IR spectra is given in Tables 2 and 3. Results from the definition of the internal coordinates used in these calculations and from the normal coordinate analyses for the relevant conformers of the two molecules are provided as Supporting Information.

In vibrational spectra, the presence as well as the absence of absorption bands at certain positions can be an important factor in the assignment. As is predicted by calculations of barriers (Figures 2 and 3$)$, in both the $(R, S)$ and $(S, S)$ compounds, the 


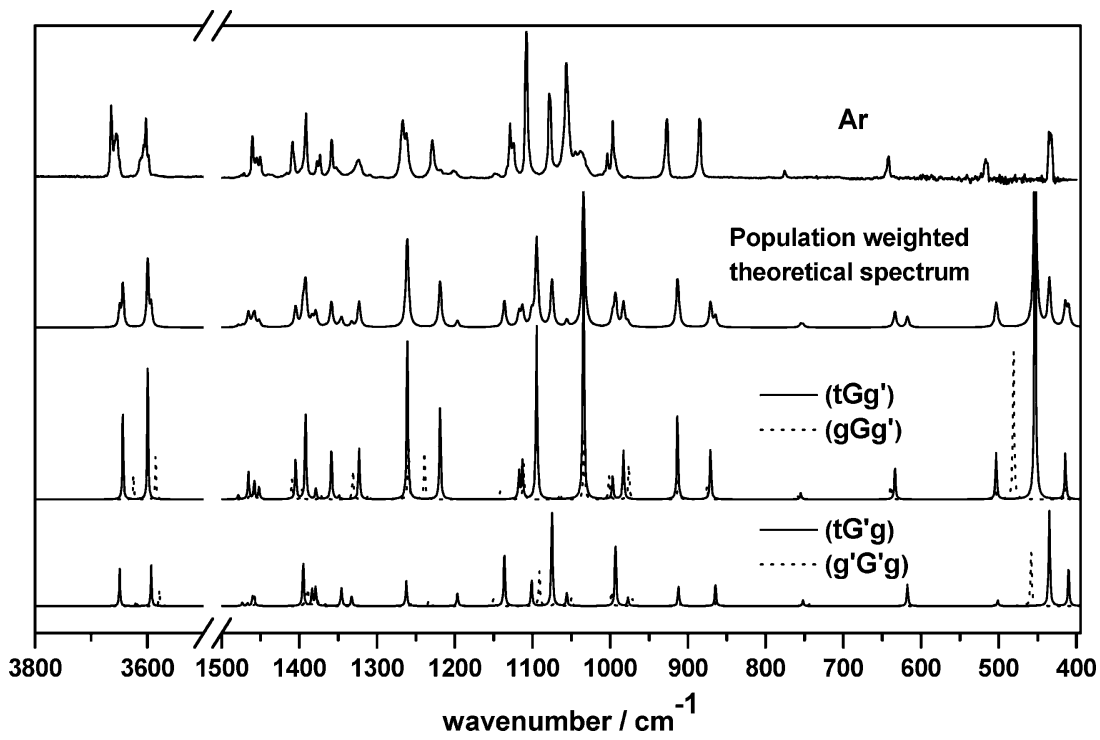

Figure 4. Infrared spectra of $(R, S)-2,3-\mathrm{BD}$ in an Ar matrix $(T=10 \mathrm{~K})$, gas-phase population weighted theoretical spectrum, and calculated spectra for the most relevant conformers, obtained at the B3LYP/6-311++G** level of theory. The calculated gas-phase spectrum was obtained by adding the spectra of conformers I and III (shown by solid lines), weighted by their respective abundances. Because conformational conversion is assumed to occur during deposition (see text for details), the abundances of conformers I ( $\mathrm{tGg}^{\prime}$ ) and III ( $\mathrm{tG}^{\prime} \mathrm{g}$ ) used to scale the calculated intensities were recalculated by adding the Boltzmann populations of conformers II $\left(\mathrm{gGg}^{\prime}\right)$ and IV $\left(\mathrm{g}^{\prime} \mathrm{G}^{\prime} \mathrm{g}\right)$, respectively. The latter two forms (their spectra shown by dashed lines) do not contribute to the population weighted theoretical spectrum. Calculated spectra were simulated using Lorentzian functions centered at the calculated (scaled) frequency and with bandwidth-at-half-height equal to $2 \mathrm{~cm}^{-1}$ (conformers' spectra) and $4 \mathrm{~cm}^{-1}$ (population weighted theoretical spectrum).

TABLE 2: Experimental and Calculated (B3LYP/6-311 $\left.++G^{* *}\right)$ Wavenumbers $\left(\mathrm{cm}^{-1}\right)$ and Intensities for the Isolated Monomeric Forms of $(R, S)-2,3-B D$

\begin{tabular}{|c|c|c|c|c|c|}
\hline $\begin{array}{l}\text { experimental } \\
\text { Ar matrix }\end{array}$ & calculated $^{b}$ & assignment $^{c}$ & $\begin{array}{l}\text { experimental } \\
\text { Ar matrix }{ }^{a}\end{array}$ & calculated $^{b}$ & assignment $^{c}$ \\
\hline $3664(\mathrm{~m})$ & & & $1352(\mathrm{vw})$ & $1346(4)$ & $\delta \mathrm{C}(3) \mathrm{H}(\mathrm{III})$ \\
\hline $3658(w)$ & 3644 (19) & $v \mathrm{O}(2) \mathrm{H}(\mathrm{I})$ & $1323(\mathrm{vw})$ & $1323(11)$ & $\gamma \mathrm{C}(2) \mathrm{H}(\mathrm{I})$ \\
\hline $3655(w)$ & $3649(9)$ & $v \mathrm{O}(2) \mathrm{H}(\mathrm{III})$ & $1310(\mathrm{vw})$ & - & - \\
\hline $3653(\mathrm{w}, \mathrm{sh})$ & & & $1267(\mathrm{~m})$ & $1261(53)$ & $\delta \mathrm{CO}(3) \mathrm{H}(\mathrm{I})+\gamma \mathrm{C}(4) \mathrm{H}_{3}{ }^{\prime}(\mathrm{I})$ \\
\hline $3613(\mathrm{vw})$ & & & $1262(w)$ & - & - \\
\hline $3611(\mathrm{vw})$ & & & $1229(\mathrm{w})$ & $1219(21)$ & $\delta \mathrm{C}(2) \mathrm{H}(\mathrm{I})$ \\
\hline $3607(w)$ & $3599(30)$ & $\nu \mathrm{O}(3) \mathrm{H}(1)$ & $1218(\mathrm{vw})$ & - & - \\
\hline $3603(\mathrm{~m})$ & $3593(9)$ & $v \mathrm{O}(3) \mathrm{H}(\mathrm{III})$ & $1200(\mathrm{vw})$ & $1197(3)$ & $\delta \mathrm{CO}(2) \mathrm{H}(\mathrm{III})$ \\
\hline $3598(\mathrm{vw})$ & & & $1147(\mathrm{vw})$ & $1136(12)$ & $\gamma \mathrm{C}(1) \mathrm{H}_{3}^{\prime \prime}(\mathrm{III})$ \\
\hline $2992(w)$ & & & $1129(\mathrm{w})$ & $1117(6)$ & $\gamma \mathrm{C}(1) \mathrm{H}_{3}^{\prime}(\mathrm{I})$ \\
\hline $2972(\mathrm{w})$ & & & $1124(\mathrm{w})$ & $1113(9)$ & $\gamma \mathrm{C}(4) \mathrm{H}_{3}{ }^{\prime \prime}(\mathrm{I})$ \\
\hline $2942(w)$ & - & $v \mathrm{CH}_{3}+v \mathrm{CH}$ & 1108 (vs) & $1095(40)$ & $\delta \mathrm{CO}(2) \mathrm{H}(\mathrm{I})$ \\
\hline $2932(w)$ & & & $1079(\mathrm{~m})$ & & $\gamma \mathrm{C}(4) \mathrm{H}_{3}^{\prime \prime}(\mathrm{III})$ \\
\hline \multirow[t]{2}{*}{$2906(w)$} & & & $1077(\mathrm{~m})$ & $1075(20)$ & \\
\hline & & & $1057(\mathrm{~s})$ & $1034(61)$ & $v \mathrm{C}(3) \mathrm{C}(4)(\mathrm{I})$ \\
\hline $1475(\mathrm{vw})$ & $1478(1)$ & $\delta \mathrm{C}(4) \mathrm{H}_{3}$ as." (I) & $1045(\mathrm{vw})$ & - & - \\
\hline $1472(\mathrm{vw})$ & $1473(1)$ & $\delta \mathrm{C}(4) \mathrm{H}_{3}$ as." (III) & $1038(\mathrm{vw})$ & - & - \\
\hline $1460(w)$ & $1466(6)$ & $\delta \mathrm{C}(1) \mathrm{H}_{3}$ as." (I) & $1004(-(4)$ & $997(5)$ & $\gamma \mathrm{C}(1) \mathrm{H}_{3}{ }^{\prime \prime}(\mathrm{I})$ \\
\hline $1455(\mathrm{vw})$ & $1458(4)$ & $\delta \mathrm{C}(1) \mathrm{H}_{3}$ as.' (I) & $1004(\mathrm{VW})$ & $993(14)$ & $\gamma \mathrm{C}(4) \mathrm{H}_{3}{ }^{\prime}(\mathrm{III})$ \\
\hline $1450(\mathrm{vw})$ & $1452(3)$ & $\delta \mathrm{C}(4) \mathrm{H}_{3}$ as.' $^{\prime}(\mathrm{I})$ & $997(\mathrm{~m})$ & $983(11)$ & $v \mathrm{C}(2) \mathrm{C}(1)(\mathrm{I})$ \\
\hline $1409(w)$ & $1405(9)$ & $\delta \mathrm{CO}(3) \mathrm{H}(\mathrm{I})$ & $927(\mathrm{~m})$ & 913 (19) & $\nu \mathrm{CO}(3)(\mathrm{I})$ \\
\hline $1392(\mathrm{~m})$ & $1392(19)$ & $\delta \mathrm{C}(1) \mathrm{H}_{3}$ s. (I) & $886(\mathrm{~m})$ & $871(11)$ & $v \operatorname{CO}(2)(\mathrm{I})$ \\
\hline $1377(\mathrm{vw})$ & $1384(3)$ & $\gamma \mathrm{C}(2) \mathrm{H}(\mathrm{III})$ & $884(\mathrm{~m})$ & $865(5)$ & $v \mathrm{CO}(2)(\mathrm{III})$ \\
\hline \multirow{3}{*}{1374 (vw) } & $1379(3)$ & $\delta \mathrm{C}(4) \mathrm{H}_{3}$ s. (I) & & $755(1)$ & $v \mathrm{C}(3) \mathrm{C}(2)(\mathrm{I})$ \\
\hline & $1379(4)$ & $\delta \mathrm{C}(1) \mathrm{H}_{3}$ s. (III) & $776(\mathrm{vw})$ & $752(1)$ & $v \mathrm{C}(3) \mathrm{C}(2)(\mathrm{III})$ \\
\hline & & & $642(\mathrm{vw})$ & $634(7)$ & $\gamma_{2} \mathrm{CC}(\mathrm{C}) \mathrm{O}(\mathrm{I})$ \\
\hline \multirow[t]{2}{*}{$1358(w)$} & $1359(11)$ & $\delta \mathrm{C}(3) \mathrm{H}(\mathrm{I})$ & $517(\mathrm{vw})$ & $503(10)$ & $\gamma_{1} \mathrm{CC}(\mathrm{C}) \mathrm{O}(\mathrm{I})$ \\
\hline & & & $434(w)$ & $453(84)$ & $\tau \mathrm{O}(3) \mathrm{H}$ \\
\hline
\end{tabular}

${ }^{a}$ Intensities are given in a qualitative way: vs, very strong; s, strong; m, medium; w, weak; vw, very weak; sh, shoulder. ${ }^{b}$ Calculated wavenumbers are scaled by the following scaling factors: 0.948 for the $\mathrm{OH}$-stretching region and 0.978 for all the other vibrations. Calculated intensities (km $\mathrm{mol}^{-1}$ ) are given in brackets and are scaled by the populations (see caption of Figure 4 for details). ${ }^{c}$ Assignment based on the comparison of the calculated spectra of conformers I and III with the experimental spectrum and taking into account the PEDs obtained for conformers I and III. Abbreviations: $\nu$, stretching; $\delta$, bending; $\gamma$, rocking; $\tau$, torsion; s, symmetric; as, asymmetric.

conformers $\mathrm{gGg}^{\prime}$ and $\mathrm{g}^{\prime} \mathrm{G}^{\prime} \mathrm{g}$ are very probable candidates for conformational cooling. Thus, the first analysis of the experimental spectra was carried out from the viewpoint of presence of the vibrational bands characteristic of these two forms. A very characteristic strong band with an intrinsic intensity of $153.4 \mathrm{~km} \mathrm{~mol}^{-1}$ is predicted at $481 \mathrm{~cm}^{-1}$ for the $\tau \mathrm{O}^{\mathrm{D}} \mathrm{H}$ vibration of the $\mathrm{gGg}^{\prime}$ form in the $(R, S)$ compound (see Figure 4). The counterpart of this band is absent in the experimental matrix 
TABLE 3: Experimental and Calculated (B3LYP/6-311++G**) Wavenumbers $\left(\mathrm{cm}^{-1}\right)$ and Intensities for the Isolated Monomeric Forms of $(S, S)$-2,3-bd

\begin{tabular}{|c|c|c|c|c|c|c|c|}
\hline \multicolumn{2}{|c|}{ experimental $^{a}$} & \multirow[b]{2}{*}{ calculated $^{b}$} & \multicolumn{2}{|l|}{ experimental $^{a}$} & \multirow[b]{2}{*}{$\mathrm{Xe}$} & \multirow[b]{2}{*}{ calculated $^{b}$} & \multirow[b]{2}{*}{ assignment $^{c}$} \\
\hline $\mathrm{Ar}$ & $\mathrm{Xe}$ & & assignment $^{c}$ & $\mathrm{Ar}$ & & & \\
\hline $3657(\mathrm{~m})$ & $3640(\mathrm{~m})$ & $3648(28)$ & $v \mathrm{O}(2) \mathrm{H}(\mathrm{I})$ & $1155(w)$ & $1151(w)$ & $1143(8)$ & $\gamma \mathrm{C}(4) \mathrm{H} 3^{\prime \prime}(\mathrm{III})$ \\
\hline $3654(\mathrm{~m})$ & $3633(\mathrm{~m})$ & $3648(7)$ & $\nu \mathrm{O}(2) \mathrm{H}(\mathrm{III})$ & $1133(\mathrm{~m})$ & $1129(\mathrm{~m})$ & 1123 (17) & $v \mathrm{CO}(3)(\mathrm{I})$ \\
\hline 3607 (w) & 3597 (vw) & $3596(43)$ & $\nu \mathrm{O}(3) \mathrm{H}(\mathrm{I})$ & $1117(w)$ & $1116(w)$ & 1107 (12) & $\gamma \mathrm{C}(1) \mathrm{H}^{\prime \prime \prime}(\mathrm{I})$ \\
\hline $3602(\mathrm{~m})$ & $3587(w)$ & $\begin{array}{l}3590(43) \\
3592(8)\end{array}$ & $v \mathrm{O}(3) \mathrm{H}(\mathrm{III})$ & 1103 (vs) & 1100 (vs) & $1086(52)$ & $\gamma \mathrm{C}(1) \mathrm{H}^{\prime}(\mathrm{I})$ \\
\hline 3590 (vw) & $3583(w)$ & & & $1085(\mathrm{vw})$ & - & - & - \\
\hline $2983(\mathrm{~m})$ & $2973(\mathrm{~m})$ & & & $1080(w)$ & $1079(w)$ & 1074 & $\gamma \mathrm{C}(4) \mathrm{H} 3^{\prime}$ (III) \\
\hline 2941 (vw) & $2930(\mathrm{vw})$ & & & $1078(\mathrm{sh}, \mathrm{w})$ & $1076(w)$ & - & - \\
\hline 2920 (vw) & - & - & $\nu \mathrm{CH}_{3}+v \mathrm{CH}$ & - & $1073(\mathrm{sh}, \mathrm{vw})$ & - & - \\
\hline 2897 (vw) & $2888(w)$ & & & - & 1069 (vw) & - & - \\
\hline 2885 (vw) & $2879(w)$ & & & $1062(\mathrm{vw})$ & - & - & - \\
\hline 1466 (vw) & - & 1469 (2) & $\delta \mathrm{C}(4) \mathrm{H}_{3}$ as." (I) & $1057(w)$ & $1056(\mathrm{~m})$ & - & - \\
\hline $1460(\mathrm{sh}, \mathrm{vw})$ & - & - & - & 1051 (vs) & 1049 (vs) & $1033(74)$ & $\nu \mathrm{C}(3) \mathrm{C}(4)(\mathrm{I})$ \\
\hline 1457 (vw) & 1455 (vw) & $1465(2)$ & $\delta \mathrm{C}(1) \mathrm{H}_{3}$ as.' (I) & $1049(\mathrm{sh}, \mathrm{m})$ & $1046(\mathrm{sh}, \mathrm{m})$ & - & - \\
\hline $1456(\mathrm{vw})$ & $1450(\mathrm{vw})$ & $1462(5)$ & $\delta \mathrm{C}(1) \mathrm{H}_{3}$ as." (I) & & & $994(4)$ & $\gamma \mathrm{C}(1) \mathrm{H} 3^{\prime}(\mathrm{III})$ \\
\hline $1448(w)$ & $1444(w)$ & 1454 & $\delta \mathrm{C}(4) \mathrm{H}_{3}$ as.' (I) & 998 (W) & 994 (W) & 985 (9) & $v \mathrm{CO}(2)(\mathrm{III})$ \\
\hline $1403(\mathrm{~m})$ & $1401(\mathrm{~m})$ & $1400(23)$ & $\delta \mathrm{CO}(3) \mathrm{H}(\mathrm{I})$ & 975 (vw) & - & - & - \\
\hline 1390 (vw) & $1385(w)$ & $1385(10)$ & $\delta \mathrm{C}(4) \mathrm{H}_{3}$ s. (I) & 964 (vw) & 963 (vw) & $955(3)$ & $\gamma \mathrm{C}(4) \mathrm{H}^{\prime}{ }^{\prime}(\mathrm{I})$ \\
\hline $1377(w)$ & $1374(w)$ & $1377(2)$ & $\delta \mathrm{C}(1) \mathrm{H}_{3}$ s. (I) & 937 (vw) & 938 (vw) & $921(4)$ & $v \mathrm{CO}(3)(\mathrm{III})$ \\
\hline- & $1368(w)$ & - & - & - & $927(\mathrm{sh}, \mathrm{w})$ & - & - \\
\hline 1360 (vw) & $1357(w)$ & $1362(4)$ & $\gamma \mathrm{C}(3) \mathrm{H}(\mathrm{I})$ & $928(\mathrm{~m})$ & 925 (m) & $913(20)$ & $\gamma \mathrm{C}(4) \mathrm{H}^{\prime \prime}(\mathrm{I})$ \\
\hline 1347 (vw) & $1342(\mathrm{vw})$ & $1344(5)$ & $\gamma \mathrm{C}(2) \mathrm{H}(\mathrm{I})$ & - & $889(w)$ & - & - \\
\hline 1323 (vw) & 1319 (vw) & $1315(22)$ & $\delta \mathrm{C}(2) \mathrm{H}(\mathrm{I})$ & $889(w)$ & $886(w)$ & 874 (14) & $v \mathrm{CO}(2)(\mathrm{I})$ \\
\hline 1313 (sh,vw) & 1309 (sh,vw) & - & - & $882(\mathrm{vw})$ & 883 (vw) & 867 & 4) (III) \\
\hline 1288 (vw) & $1288(\mathrm{vw})$ & $1283(5)$ & $\delta \mathrm{CO}(3) \mathrm{H}(\mathrm{III})$ & 881 (vw) & - & $007(4$ & (ग) (4) (III) \\
\hline $1270(\mathrm{sh}, \mathrm{w})$ & $1270(w)$ & - & - & - & $811(\mathrm{vw})$ & $795(1)$ & $v \mathrm{C}(2) \mathrm{C}(3)(\mathrm{I})$ \\
\hline 1267 (m) & $1265(\mathrm{~m})$ & $1260(47)$ & $\delta \mathrm{C}(3) \mathrm{H}(\mathrm{I})+\delta \mathrm{CO}(3) \mathrm{H}(\mathrm{I})$ & - & 766 (vw) & $748(1)$ & $v \mathrm{C}(2) \mathrm{C}(3)(\mathrm{III})$ \\
\hline $1265(\mathrm{sh}, \mathrm{w})$ & $1261(\mathrm{sh}, \mathrm{w})$ & - & - & 659 (vw) & $661(\mathrm{vw})$ & $650(4)$ & $\gamma_{2} \mathrm{CC}(\mathrm{C}) \mathrm{O}(\mathrm{III})$ \\
\hline 1226 (vw) & $1226(\mathrm{vw})$ & $1219(14)$ & $\delta \mathrm{CO}(2) \mathrm{H}(\mathrm{I})$ & $542(w)$ & $541(w)$ & $531(11)$ & $\gamma_{4} \mathrm{CC}(\mathrm{C}) \mathrm{O}(\mathrm{I})$ \\
\hline \multirow[t]{2}{*}{$1190(\mathrm{vw})$} & 1188 (vw) & $1178(6)$ & $\delta \mathrm{CO}(2) \mathrm{H}(\mathrm{III})$ & $501(\mathrm{vw})$ & $501(\mathrm{vw})$ & $488(40)$ & $\delta \mathrm{CCO}(3)(\mathrm{I})$ \\
\hline & & & & $430(w)$ & $432(w)$ & $\begin{array}{l}462(66) \\
439(19)\end{array}$ & $\begin{array}{l}\tau \mathrm{O}(3) \mathrm{H}(\mathrm{I}) \\
\tau \mathrm{O}(3) \mathrm{H}(\mathrm{III})\end{array}$ \\
\hline
\end{tabular}

\footnotetext{
${ }^{a}$ Intensities are given in a qualitative way: vs, very strong; s, strong; m, medium; w, weak; vw, very weak; sh,shoulder. ${ }^{b}$ Calculated wavenumbers are scaled by the following scaling factors: 0.948 for the $\mathrm{OH}$-stretching region and 0.978 for all the other vibrations. Calculated intensities (km $\mathrm{mol}^{-1}$ ) are given in brackets and are scaled by the populations (see caption of Figure 5 for details). ${ }^{c}$ Assignment based on the comparison of the calculated spectra of conformers I and III with the experimental spectrum and taking into account the PEDs obtained for conformers I and III. Abbreviations: $\nu$, stretching; $\delta$, bending; $\gamma$, rocking; $\tau$, torsion; s, symmetric; as, asymmetric.
}

spectrum. Another vibration of the $\mathrm{gGg}^{\prime}$ form, $\delta \mathrm{O}^{\mathrm{A}} \mathrm{H}$, with calculated intensity $48.9 \mathrm{~km} \mathrm{~mol}^{-1}$, is predicted at $1239 \mathrm{~cm}^{-1}$. The experimental spectrum does not exhibit a corresponding vibration either. The absence of these two, and few other weaker absorptions, suggests that the $\mathrm{gGg}^{\prime}$ (the second energy form, according to the present calculations) has undergone conformational cooling during the deposition of the matrix. A positive confirmation to this hypothesis is that during annealing of the matrixes, no visible changes in the spectra of monomers occurred until aggregation started. The absence in the freshly deposited samples of the fourth energy conformer, g' $\mathrm{G}^{\prime} \mathrm{g}$, is more difficult to prove experimentally, because its characteristic strong absorption bands coincide in frequency either with $\mathrm{tGg}^{\prime}$ or with $\mathrm{tG}^{\prime} \mathrm{g}$ (see Figure 4). However, the similarity of the theoretically predicted barriers for conformational cooling (see Figure 2) also suggests that, with all probability, the $\mathrm{g}^{\prime} \mathrm{G}^{\prime} \mathrm{g}$ form relaxed into $\mathrm{tG}^{\prime} \mathrm{g}$ during matrix deposition.

A very similar situation happens in the $(S, S)$ compound. Strong bands with intensities 151.4 and $84.2 \mathrm{~km} \mathrm{~mol}^{-1}$ are predicted to appear at 521.7 and $1271.0 \mathrm{~cm}^{-1}$. These bands correspond to the $\tau \mathrm{O}^{\mathrm{D}} \mathrm{H}$ and $\delta \mathrm{O}^{\mathrm{D}} \mathrm{H}$ vibrations of the $\mathrm{gGg}^{\prime}$ form and do not have counterparts in the experimental spectra (Figure 5). The lack of change of the experimental spectra during annealing of the samples was again a definite proof for the conformational cooling of the $\mathrm{gGg}^{\prime}$ form (the second most stable), which also occurred during the deposition of the sample, like in the case of the $(R, S)$ compound. There are also no doubts about conformational cooling of the $\mathrm{g}^{\prime} \mathrm{G}^{\prime} \mathrm{g}$ form in the $(S, S)$ compound, because it has the lowest of all predicted barriers to conformational conversion, only $2.2 \mathrm{~kJ} \mathrm{~mol}^{-1}$ (see Figure 3).

A similar behavior had already been observed for related molecules such as pinacol (2,3-dimethyl-2,3-butanediol) ${ }^{48}$ and other systems with conformers separated by low-energy barriers. ${ }^{44}$ Interestingly, infrared spectroscopy studies on 1,2ethanediol carried out in a low-temperature argon matrix (18 $\mathrm{K}$ ) show that both $\mathrm{tGg}^{\prime}$ and $\mathrm{gGg}^{\prime}$ forms were found to be trapped in the matrix. ${ }^{49,50}$ This situation could have easily been explained if two almost isoenergetical species were separated by a very low barrier and then were in the true thermodynamic equilibrium in the matrix. Indeed, theoretical calculations predict a lowenergy barrier (ca. $5 \mathrm{~kJ} \mathrm{~mol}^{-1}$ ) and approximately equal energies for the two most stable 1,2-ethanediol conformers. ${ }^{21,40}$ However, recent experimental studies in the gas phase ${ }^{51}$ suggest "an energy difference of $\sim 2.5 \mathrm{~kJ} \mathrm{~mol}^{-1}$ " between these conformers and, at this energy difference, the equilibrium thermal population of the minor form would be negligible at $18 \mathrm{~K}$. In view of the present results on 2,3-BD, this discrepancy between the theory, matrix isolation results, and gas-phase data for 1,2-ethanediol opens space for further investigation on this molecule.

In 2,3-BD, after relaxation in matrixes, forms $\mathrm{gGg}^{\prime}$ and $\mathrm{g}^{\prime} \mathrm{G}^{\prime} \mathrm{g}$ convert (in both stereoisomers they are calculated as the second and fourth most stable) into their lower-energy counterparts, $\mathrm{tGg}^{\prime}$ and $\mathrm{tG}^{\prime} \mathrm{g}$ (the first and third most stable), respectively. In such a situation, conformational populations of forms $\mathrm{tGg}^{\prime}$ and $\mathrm{tG}^{\prime} \mathrm{g}$ in matrixes should be equal to their populations in the equilibrium gaseous phase augmented by populations of forms 


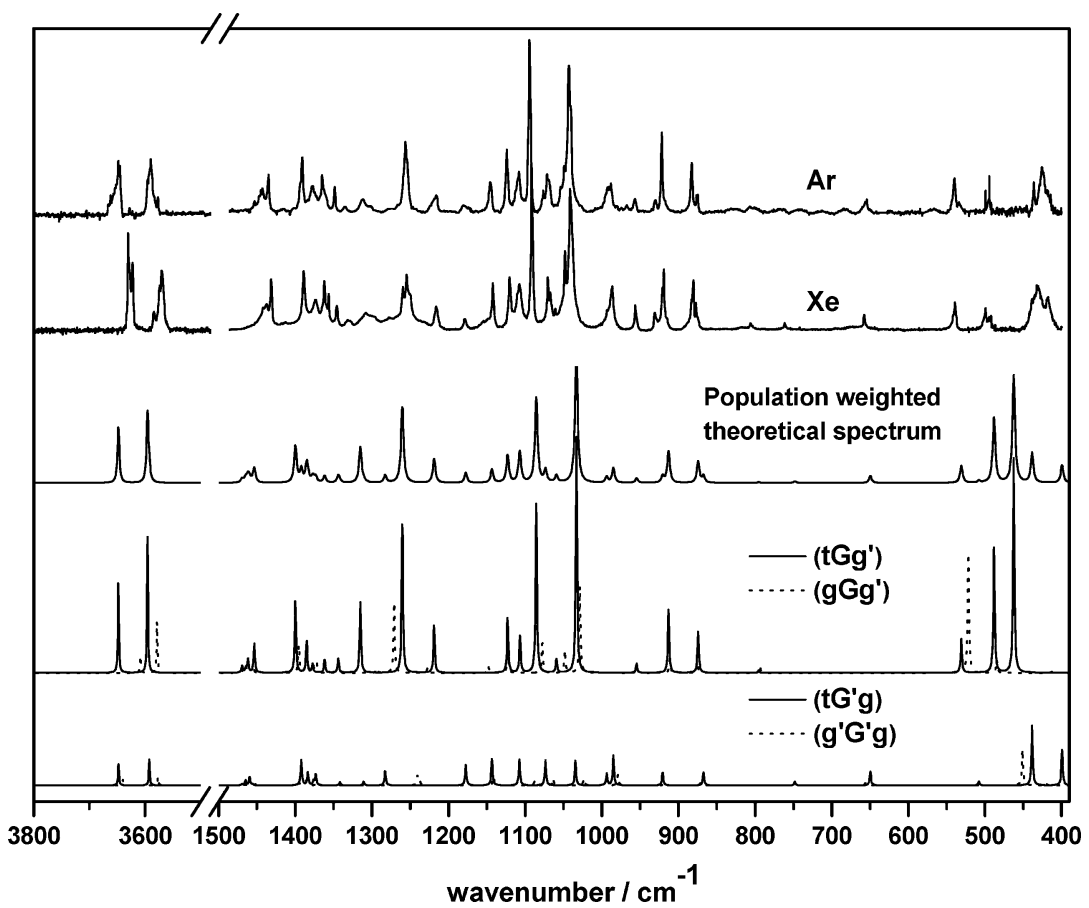

Figure 5. Infrared spectra of $(S, S)-2,3-\mathrm{BD}$ in $\mathrm{Ar}(T=10 \mathrm{~K})$ and $\mathrm{Xe}(T=20 \mathrm{~K})$ matrixes, gas-phase population weighted theoretical spectrum, and calculated spectra for the most relevant conformers, obtained at the B3LYP/6-311++G** level of theory. The calculated gas-phase spectrum was obtained by adding the spectra of conformers I and III (shown by solid lines) weighted by their respective abundances. Because conformational conversion is assumed to occur during deposition (see text for details), the abundances of conformers I ( $\mathrm{tGg}^{\prime}$ ) and III (tG'g) used to scale the calculated intensities were recalculated by adding the Boltzmann populations of conformers II ( $\left.\mathrm{gGg}^{\prime}\right)$ and IV ( $\mathrm{g}^{\prime} \mathrm{G}^{\prime} \mathrm{g}$ ), respectively. The latter two forms (their spectra shown by dashed lines) do not contribute to the population weighted theoretical spectrum. Calculated spectra were simulated using Lorentzian functions centered at the calculated (scaled) frequency and with bandwidth-at-half-height equal to $2 \mathrm{~cm}^{-1}$ (conformers' spectra) and $4 \mathrm{~cm}^{-1}$ (population weighted theoretical spectrum).

$\mathrm{gGg}^{\prime}$ and $\mathrm{g}^{\prime} \mathrm{G}^{\prime} \mathrm{g}$. In this manner, the population-weighted theoretical spectra were constructed for the $(R, S)$ and $(S, S)$ compounds, and they are compared in Figures 4 and 5 with the respective experimental matrix spectra. At first glance, one can see a fairly good agreement between theory and experiment. This close match proves the ability of the B3LYP functional combined with the $6-311++\mathrm{G}^{* *}$ basis set to predict the conformational equilibrium of simple intramolecular hydrogenbonded systems as the vicinal butanediols. Accurate theoretical spectra play a key role in the assignment of the vibration bands recorded for the studied molecules and in their characterization from a structural point of view.

According to the DFT calculations, only the four most stable conformers of $(S, S)-2,3-\mathrm{BD}$ and $(R, S)-2,3-\mathrm{BD}$ should contribute significantly to the conformational equilibrium at $295 \mathrm{~K}$ (nozzle temperature in the matrix isolation experiments). These conformers are exactly those able to originate internal hydrogen bonds. Taking into consideration all data discussed above, only the calculated spectra of conformers I and III were considered in the detailed interpretation of the spectra of the two diastereomers of 2,3-butanediol. The matrix-isolation spectra of these compounds are constituted essentially by absorption bands due to the $\mathrm{tGg}^{\prime}$ conformer, although some bands ascribed to the $\mathrm{tG}^{\prime} \mathrm{g}$ conformer are also present, as shown in Tables 2 and 3. The experimental observation of the $\mathrm{tGg}^{\prime}$ and $\mathrm{tG}^{\prime} \mathrm{g}$ conformers and nonobservation of the $\mathrm{gGg}^{\prime}$ and $\mathrm{g}^{\prime} \mathrm{G}^{\prime} \mathrm{g}$ forms is then a strong argument in favor of accuracy of theoretical predictions of the relative energies, even at the DFT level, with the used basis sets (with polarization and diffusion functions on all atoms). The present results also show that calculations of the relative energies with smaller basis sets without polarization/diffusion functions on hydrogen atoms $\left(6-31 \mathrm{G}^{*}\right)$ are not sufficient for correct predictions. ${ }^{17}$
The remaining conformational interconversions that might occur in the matrixes after their deposition, can only involve conformers of type I and III. To study the possibility of such conversions, barriers separating these conformers were studied theoretically as well. The results are presented in Figure 6. One can see that the barrier to intramolecular conversion from $\mathrm{tG}^{\prime} \mathrm{g}$ to $\mathrm{tGg}^{\prime}$ in the $(S, S)$ compound is about $18 \mathrm{~kJ} \mathrm{~mol}^{-1}$, whereas in the $(R, S)$ compound, this barrier is much higher, more than 27 $\mathrm{kJ} \mathrm{mol}^{-1}$. From the viewpoint of the conformational cooling, these barriers are very high; they imply rearrangements of the heavy atom backbone of molecules. To possibly observe molecular rearrangements corresponding to such high barriers, it is necessary to use the matrix gas with the best relaxant properties, i.e., xenon, and perform annealing of the samples to maximally possible temperatures. Between the two stereoisomers of 2,3-BD, the natural candidate to perform such a test is the compound with a lower barrier. That is why the $(S, S)$ isomer was deposited into the xenon matrix at $20 \mathrm{~K}$ (Figure 5) and annealing of this sample up to $65 \mathrm{~K}$ was carried out. The temperature increase did not produce any significant spectral changes. This behavior shows that a barrier of $18 \mathrm{~kJ} \mathrm{~mol}^{-1}$ separating conformers $\mathrm{tG}^{\prime} \mathrm{g}$ and $\mathrm{tGg}^{\prime}$ is high enough to prevent the conversion of the former into the latter, even in a xenon matrix within the whole range of accessible temperatures (until the disappearance of the sample). The nonobservation of the interconversion between conformers separated by a barrier of $18 \mathrm{~kJ} \mathrm{~mol}^{-1}$ is not surprising. Recently we have studied trimethyl phosphate, a molecule where the two lowest energy forms are separated by a barrier less than $10 \mathrm{~kJ} \mathrm{~mol}^{-1} .52$ Conformational relaxation between these forms was only possible to observe in xenon matrixes after their annealing up to $50 \mathrm{~K}$, i.e., close to the highest possible temperature of existence of a xenon matrix. 


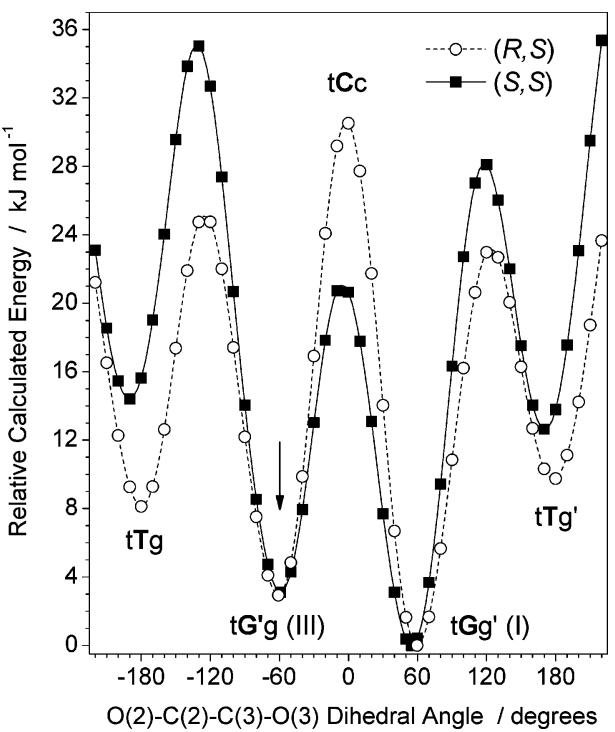

Figure 6. Potential energy profiles for intramolecular rotation of the heavy atom backbone in two diastereoisomers of 2,3-BD, $(S, S)$ (solid line) and $(R, S)$ (dashed line). For each point, the $\mathrm{O}-\mathrm{C}-\mathrm{C}-\mathrm{O}$ dihedral angle was kept fixed, whereas all the other internal coordinates were optimized at the B3LYP/6-311++ $\mathrm{G}^{* *}$ level of theory. The dihedral angles corresponding to the reaction coordinates are shown by bold letters in conformer names. Conformer names apply to both compounds. The starting geometry for both scans corresponds to the third-by-energy conformer $\left(\mathrm{tG}^{\prime} \mathrm{g}\right)$ and is indicated by an arrow. The zero-levels of energy were chosen for both compounds to correspond to the electronic energy of the most stable conformer ( $\left.\mathrm{tGg}^{\prime}\right)$ without the zero-point vibrational energy correction.

In the present study, annealing only resulted in the disappearance of some sharp bands, being replaced by broader bands. This observation confirms the formation of aggregates during annealing. This is particularly evident in the OH-stretching region, where the intensity of the two monomeric bands considerably decreases, whereas a broad band located between 3390 and $3330 \mathrm{~cm}^{-1}$ grows as the temperature increases.

It appears also interesting to comment on the shape of the barriers presented in Figure 6 . Whereas the $\mathrm{tG}^{\prime} \mathrm{g}$ and $\mathrm{tGg}^{\prime}$ minima are very close in energy, all other stationary points are located far from each other on the energy scale in the two isomers. The reason for such differences is the chirality of 2,3BD. For the transition state, where the $\mathrm{O}-\mathrm{C}-\mathrm{C}-\mathrm{O}$ dihedral angle is equal to $0^{\circ}$, the two $\mathrm{OH}$ groups are obviously in the eclipsed position. In the $(S, S)$ compound, in this geometry with two $\mathrm{OH}$ groups eclipsed, the two methyl groups become eclipsed with the two hydrogen atoms, i.e., the $\mathrm{C}-\mathrm{C}-\mathrm{C}-\mathrm{C}$ dihedral angle is equal ca. $-120^{\circ}$. In the $(R, S)$ compound, on the contrary, when the $\mathrm{O}-\mathrm{C}-\mathrm{C}-\mathrm{O}$ axis assumes the cis orientation, the eclipsed pairs of remaining groups are methyl/methyl and hydrogen/hydrogen. It is clear that the steric repulsion between the two eclipsed methyl groups is much higher than the repulsion between a methyl group eclipsed with a hydrogen atom. This is the reason of the very big difference in the energies of the transition states designated as tCc in Figure 6. Another interesting observation is that in the abscissa range from $-60^{\circ}$ to $+60^{\circ}$ the intramolecular hydrogen bond is always preserved. This results in a change of the orientation of the $\mathrm{O}^{\mathrm{D}} \mathrm{H}$ group from the $\mathrm{g}$ (via cis) to the $\mathrm{g}^{\prime}$ position, whereas the heavy atom backbone rearranges simultaneously from $\mathrm{G}^{\prime}$ (via $\mathrm{Cis}$ ) to $\mathrm{G}$. Further rotation of the backbone (from $-60^{\circ}$, in the negative direction, or from $+60^{\circ}$, in the positive direction) does not change the orientation of the $\mathrm{OH}$ group, because the intramolecular hydrogen bond becomes broken.
The heights of other maxima on the potential energy profiles corresponding to the change of the molecular backbone can also be explained in terms of steric repulsions between the eclipsed groups. For the $(R, S)$ compound, when the $\mathrm{O}-\mathrm{C}-\mathrm{C}-\mathrm{O}$ axis assumes values of either $-120^{\circ}$ or $+120^{\circ}$, the pairs of eclipsed groups are the same: methyl/hydroxyl, methyl/hydrogen, and hydroxyl/hydrogen. That is why the repulsive interactions are similar and the respective barriers are of similar height (ca. 25 and $23 \mathrm{~kJ} \mathrm{~mol}^{-1}$, see Figure 6$)$. In the $(S, S)$ compound, the pairs of eclipsed groups at $+120^{\circ}$ are methyl/methyl and twice hydroxyl/hydrogen. Such combination results in a barrier of 28 $\mathrm{kJ} \mathrm{mol}^{-1}$. The highest calculated barrier, $35 \mathrm{~kJ} \mathrm{~mol}^{-1}$, is predicted for the $\mathrm{O}-\mathrm{C}-\mathrm{C}-\mathrm{O}$ dihedral angle equal to $-120^{\circ}$ in the $(S, S)$ isomer. In this case, the pairs of eclipsed groups are hydrogen/hydrogen and twice hydroxyl/methyl. The value of the calculated barrier suggests then that eclipsed hydroxyl and methyl groups represent the energetically less favored neighborship.

Further rotation of the heavy atom backbone toward the trans positions of the $\mathrm{O}-\mathrm{C}-\mathrm{C}-\mathrm{O}$ angle $\left( \pm 180^{\circ}\right)$ produces the high energy conformers $\mathrm{tTg}$ and $\mathrm{tTg}^{\prime}$ (Figure 6), which have been commented before and do not represent any special interest.

4.4. Estimation of the Hydrogen-bond Energy from the Vibrational Spectra. Detailed information about the structure of the isomers can be taken from the spectral vibration bands presented in Figures 4 and 5 and assigned in Tables 2 and 3. As the stretching vibration modes are more sensitive to structural features such as hydrogen bonding, particular attention is paid to this region in the following discussion.

In the $\mathrm{OH}$-stretching region, the matrix-isolation spectra of the butanediols under consideration exhibit two distinct bands, which appear as multiplets. The higher frequency band is localized between 3664 and $3653 \mathrm{~cm}^{-1}$ in argon matrix and between 3640 and $3633 \mathrm{~cm}^{-1}$ in xenon matrix. This band corresponds to the stretching vibration of the $\mathrm{OH}$ free group, in agreement with the theoretical predictions. The second $\mathrm{OH}-$ stretching band is localized between 3613 and $3597 \mathrm{~cm}^{-1}$ in argon matrix and between 3590 and $3583 \mathrm{~cm}^{-1}$ in xenon matrix. This band is attributed to the $\mathrm{OH}$ group acting as donor in a hydrogen bond.

As is well-known, a typical spectroscopic manifestation of such a bond is the red-shift of the stretching frequency of the $\mathrm{OH}$ donor group. It has been shown that the hydrogen bond enthalpy (in $\mathrm{kJ} \mathrm{mol}^{-1}$ ) and the red-shift observed in the $\mathrm{OH}$ stretching vibration $\left[\Delta(\nu \mathrm{OH})\right.$, in $\left.\mathrm{cm}^{-1}\right]$ due to the involvement of the $\mathrm{OH}$ moiety in a hydrogen bond obey the correlation $(\Delta H)^{2}=1.92\{[\Delta(\nu \mathrm{OH})]-40\} .{ }^{53}$ Such an empirical relationship has been shown to apply to different families of molecules and can be considered as a general tool to estimate enthalpies of hydrogen bonds from vibrational data. ${ }^{53,54}$ An alternative empirical correlation that has also been currently used to estimate hydrogen bond enthalpies from vibrational data uses the observed blue shift in the $\mathrm{OH}$ torsion $[\Delta(\tau \mathrm{OH})]$ resulting from involvement of the $\mathrm{OH}$ group in the hydrogen bond $\left\{-\Delta H=0.67 \Delta(\tau \mathrm{OH})^{2}\right.$, where $\Delta(\tau \mathrm{OH})^{2} \equiv 10^{-4}\left[(\tau \mathrm{OH})^{2}-\right.$ $\left.\left(\tau \mathrm{OH}^{0}\right)^{2}\right], \tau \mathrm{OH}$ is expressed in $\mathrm{cm}^{-1}$; where $\tau \mathrm{OH}^{0}$ is the frequency of the torsion in the non-hydrogen-bonded system $\left.{ }^{55,56}\right\}$. For the two molecules now studied, $\Delta(\nu \mathrm{OH})$ can be easily obtained by calculating the gravity centers of the $\mathrm{OH}$ stretching bands that originated in $\mathrm{OH}$ groups involved or not involved into the intramolecular hydrogen bond. From the spectra obtained in argon matrix, these values are 3605 and 3658 $\mathrm{cm}^{-1}$ and 3601 and $3650 \mathrm{~cm}^{-1}$, for $(R, S)$-2,3-BD and $(S, S)$ $2,3-\mathrm{BD}$, respectively. In turn, to obtain $\Delta(\tau \mathrm{OH})$, it is necessary 
to adopt a value for $\tau \mathrm{OH}^{0}$ (i.e., the $\mathrm{OH}$ torsion frequency of the $\mathrm{OH}$ group not involved in the hydrogen bond as donor), because this has a characteristic frequency below the experimentally accessible frequency range. The calculations predict this mode as absorbing at ca. $250 \mathrm{~cm}^{-1}$, and thus, this value can be used as $\tau \mathrm{OH}^{0}$ for use in the empirical correlation $[-\Delta H$ vs $\Delta(\tau \mathrm{OH})]$. The experimentally observed frequencies for the $\tau \mathrm{OH}$ mode in the two stereoisomers are 434 and 430 $\mathrm{cm}^{-1}$, respectively for $(R, S)-2,3-\mathrm{BD}$ and $(S, S)-2,3-\mathrm{BD}$. Applying both empirical correlations to these data and taking the average values for $-\Delta H$, the values 6.7 and $6.6 \mathrm{~kJ} \mathrm{~mol}^{-1}$ were obtained for $(R, S)-2,3-\mathrm{BD}$ and $(S, S)-2,3-\mathrm{BD}$, respectively. These values are very similar to the estimation made from theoretical structural data in the present study $\left(8 \mathrm{~kJ} \mathrm{~mol}^{-1}\right)$. These results are also comparable to the data obtained for 2,3-BD in the vapor phase by Fishman and Chen $\left(3 \pm 2 \mathrm{~kJ} \mathrm{~mol}^{-1}\right)^{11}$ from the temperature dependence of the IR band intensities associated with "free" and hydrogen-bonded $\mathrm{OH}$ groups, though this latter estimation of the hydrogen-bond enthalpy appears to be somewhat underestimated.

\section{Conclusions}

Theoretical calculations on the two diastereomers of 2,3-BD showed that the most relevant conformers of both molecules are characterized by the $\mathrm{O}-\mathrm{C}-\mathrm{C}-\mathrm{O}$ dihedral angle in the \pm gauche orientation, leading to the establishment of a very weak intramolecular hydrogen bond. These conformers, at room temperature, make up 89 and $96 \%$ of the equilibrium conformational composition of $(R, S)$ - and $(S, S)-2,3-\mathrm{BD}$, respectively.

Theoretical calculations carried out in this study were performed at two different levels of theory (DFT and MP2) and consistently resulted in the same relative order of energy of the most stable forms. Correctness of theoretical predictions for the structures of the most stable conformers for both considered compounds was confirmed experimentally. In view of the present results, earlier reports about the relative order of conformer stability in 2,3-butanediols should be revised.

Comparison of the theoretically calculated vibrational data with the experimental spectra of the compounds isolated in argon and xenon matrixes allowed, for the first time, the identification and vibrational characterization of two conformers trapped in the matrix: $\mathrm{tGg}^{\prime}$ and $\mathrm{tG}^{\prime} \mathrm{g}$, the first and third most stable conformers, respectively, predicted by the theoretical calculations. No evidence of bands characteristic of the $\mathrm{gGg}^{\prime}$ and $\mathrm{g}^{\prime} \mathrm{G}^{\prime} \mathrm{g}$ forms was found in the experimental spectra, which is in agreement with the relatively low heights of the barriers for the $\mathrm{gGg}^{\prime} \rightarrow \mathrm{tGg}^{\prime}$ and $\mathrm{g}^{\prime} \mathrm{G}^{\prime} \mathrm{g} \rightarrow \mathrm{tG}^{\prime} \mathrm{g}$ intercoversions (calculated values less than $4 \mathrm{~kJ} \mathrm{~mol}^{-1}$ ).

From the application of empirical correlations between the vibrational data and energetical parameters, an average value of ca. $7 \mathrm{~kJ} \mathrm{~mol}^{-1}$ was estimated for the intramolecular hydrogen bond enthalpy, which is in a good agreement with the value derived from the theoretical results $\left(8 \mathrm{~kJ} \mathrm{~mol}^{-1}\right)$.

Acknowledgment. This work was supported by Fundação para a Ciência e a Tecnologia, Lisbon: Research Project POCI/ QUI/59019/2004; Grants SFRH/BD/9110/2002; and SFRH/ BPD/1661/2000.

Supporting Information Available: Atom numbering scheme and definition of internal coordinates for $(R, S)-2,3-\mathrm{BD}$ and $(S, S)$ 2,3-BD. Calculated wavenumbers, infrared intensities, and potential energy distributions for conformers $\mathrm{I}\left(\mathrm{tGg}^{\prime}\right)$ and III
( $\left.\mathrm{tG}^{\prime} \mathrm{g}\right)$ of $(R, S)-2,3-\mathrm{BD}$ and $(S, S)-2,3-\mathrm{BD}$. This material is available free of charge via the Internet at http://pubs.acs.org.

\section{References and Notes}

(1) Crittenden, D. L.; Thompson, K. C.; Jordan, M. J. T. J. Phys. Chem. A 2005, 109, 2971.

(2) Voloch, M.; Jansen, N. B.; Ladisch, M. R.; Tsao, G. T.; Narayan, R.; Rodwell, V. W. In Comprehensive Biotechnology; Cooney, C. L., Humphrey, A. E., Eds.; Pergamon Press: Oxford, 1985; p. 934.

(3) Hatch, R. T.; Hardy, R. In A Revolution in Biotechnology; Marx, J. L., Ed.; ICSU PRESS: Cambridge, 1989.

(4) Boutron, P.; Mehl, P.; Kaufmann, A.; Angibaud, P. Cryobiology 1986, 23, 453.

(5) Boutron, P. Cryobiology 1990, 27, 55

(6) Boutron, P. Cryobiology 1992, 29, 347

(7) Larese, A.; Limandas, F.; Bourgeot, J. P.; Ehrsam, A.; Boutron, P.; Meyer, F.; Hartmann, D. Cryobiology 1989, 26, 572.

(8) Mehl, P.; Boutron, P. Cryobiology 1987, 24, 355.

(9) Soltys, K. A.; Batta, A. K.; Koneru, B. J. Surg. Res. 2001, 96, 30.

(10) Kuhn, L. P. J. Am. Chem. Soc. 1952, 74, 2492.

(11) Fishman, E.; Chen, T. L. Spectrochim. Acta, Part A 1969, 25, 1231

(12) Coleman, W. M.; Gordon, B. M. Appl. Spectrosc. 1988, 42, 671.

(13) Gallwey, F. B.; Hawkes, J. E.; Haycock, P.; Lewis, D. J. Chem. Soc.-Perkin Trans. 1990, 2, 1979.

(14) Deshmukh, M. M.; Sastry, N. V.; Gadre, S. R. J. Chem. Phys. 2004 121,12402

(15) Szarecka, A.; Hoffmann, M.; Rychlewski, J.; Rychlewska, U. J. Mol. Struct. 1996, 374, 363.

(16) Klein, R. A. J. Comput. Chem. 2002, 23, 585.

(17) Wang, F.; Polavarapu, P. L. J. Phys. Chem. A 2001, 105, 6991.

(18) van Duin, M.; Baas, J. M. A.; van de Graaf, B. J. Org. Chem 1986, 51, 1298.

(19) Vazquez, S.; Mosquera, R. A.; Rios, M. A.; van Alsenoy, C. THEOCHEM-J. Mol. Struct. 1988, 181, 149.

(20) Vazquez, S.; Mosquera, R. A.; Rios, M. A.; van Alsenoy, C THEOCHEM-J. Mol. Struct. 1989, 184, 323.

(21) Reiling, S.; Brickmann, J.; Schlenkrich, M.; Bopp, P. A. J. Comput. Chem. 1996, 17, 133.

(22) Klein, R. A. J. Comput. Chem. 2003, 24, 1120.

(23) Klein, R. A. J. Am. Chem. Soc. 2002, 124, 13931.

(24) IUPAC Compendium of Chemical Terminology, The Gold Book, 2nd ed.; McNaught, A. D., Wilkinson, A., Eds.; Blackwell Science: London, 1997.

(25) Jesus, A. J. L.; Rosado, M. T. S.; Leitão, M. L. P.; Redinha, J. S J. Phys. Chem. A 2003, 107, 3891 .

(26) Reva, I. D.; Stepanian, S. G.; Adamowicz, L.; Fausto, R. J. Phys. Chem. A 2001, 105, 4773.

(27) Becke, A. D. Phys. Rev. A 1988, 38, 3098.

(28) Becke, A. D. J. Chem. Phys. 1993, 98, 5648.

(29) Lee, C. T.; Yang, W. T.; Parr, R. G. Phys. Rev. B 1988, 37, 785.

(30) Frisch, M. J.; Head-Gordon, M.; Pople, J. A. Chem. Phys. Lett. 1990, 166,275

(31) Head-Gordon, M.; Head-Gordon, T. Chem. Phys. Lett. 1994, 220, 122.

(32) Frisch, M. J.; Head-Gordon, M.; Pople, J. A. Chem. Phys. Lett. 1990, 166, 281.

(33) Frisch, M. J.; Trucks, G. W.; Schlegel, H. B.; Scuseria, G. E.; Robb, M. A.; Cheeseman, J. R.; Zakrzewski, V. G.; Montgomery, J. A., Jr.; Stratmann, R. E.; Burant, J. C.; Dapprich, S.; Millam, J. M.; Daniels, A. D.; Kudin, K. N.; Strain, M. C.; Farkas, O.; Tomasi, J.; Barone, V.; Cossi, M.; Cammi, R.; Mennucci, B.; Pomelli, C.; Adamo, C.; Clifford, S.; Ochterski, J.; Petersson, G. A.; Ayala, P. Y.; Cui, Q.; Morokuma, K.; Malick, D. K.; Rabuck, A. D.; Raghavachari, K.; Foresman, J. B.; Cioslowski, J.; Ortiz, J. V.; Stefanov, B. B.; Liu, G.; Liashenko, A.; Piskorz, P.; Komaromi, I.; Gomperts, R.; Martin, R. L.; Fox, D. J.; Keith, T.; Al-Laham, M. A.; Peng, C. Y.; Nanayakkara, A.; Gonzalez, C.; Challacombe, M.; Gill, P. M. W.; Johnson, B. G.; Chen, W.; Wong, M. W.; Andres, J. L.; Head-Gordon, M.; Replogle, E. S.; Pople, J. A. Gaussian 98, revision A.9; Gaussian, Inc.: Pittsburgh, PA, 1998.

(34) Schachtschneider, J. H. Technical Report; Shell Development Co.: Emeryville, CA, 1969

(35) Wiberg, K. B.; Murcko, M. A.; Laidig, K. E.; MacDougall, P. J. J. Phys. Chem. 1990, 94, 6956.

(36) Rablen, P. R.; Hoffman, R. W.; Hrovat, D. A.; Borden, W. T. J. Chem. Soc.-Perkin Trans. 1999, 2, 1719.

(37) Allinger, N. L.; Hindman, D.; Honig, H. J. Am. Chem. Soc. 1977, $99,3282$.

(38) Steiner, T. Angew. Chem., Int. Ed. 2002, 41, 48.

(39) Desiraju, G. R.; Steiner, T. The Weak Hydrogen Bond In Structural Chemistry and Biology; Oxford University Press: New York, 1999.

(40) Csonka, G. I.; Csizmadia, I. G. Chem. Phys. Lett. 1995, 243, 419 
(41) Chang, Y.-P.; Su, T.-M.; Li, T.-W.; Chao, I. J. Phys. Chem. A 1997, 101, 6107.

(42) Friedemann, R.; Fengler, A.; Naumann, S.; Gromann, U. THEOCHEM-J. Mol. Struct. 1995, 357, 217.

(43) Barnes, A. J. J. Mol. Struct. 1984, 113, 161

(44) Reva, I. D.; Stepanian, S. G.; Adamowicz, L.; Fausto, R. Chem. Phys. Lett. 2003, 374, 631.

(45) For example, in cyanoacetic acid and methyl cyanoacetate, the barrier to intramolecular rotation was calculated to be equal to $3 \mathrm{~kJ} \mathrm{~mol}^{-1}$. In cyanoacetic acid, the higher energy conformer was completely depopulated in a xenon matrix deposited at $15 \mathrm{~K}$, whereas in methyl cyanoacetate the population of the higher energy form was completely preserved in a xenon matrix deposited at $20 \mathrm{~K}$. The only structural difference between the two compounds was the substitution of the hydrogen atom of the carboxyl group by the methyl group. For cyanoacetic acid, the compound with the lighter group undergoing rearrangement, it was only just possible to approach the conformational population characteristic of the gaseous phase at the lowest possible temperature of the matrix substrate (ca. $10 \mathrm{~K}$ ) and using argon as the matrix gas. The above examples show that knowing the barriers to intramolecular rotation is extremely important when analyzing the conformational populations of matrix-isolated compound.

(46) Andrzejewska, A.; Lapinski, L.; Reva, I.; Fausto, R. Phys. Chem. Chem. Phys. 2002, 4, 3289.

(47) Scott, A. P.; Radom, L. J. Phys. Chem. 1996, 100, 16502.

(48) Dahlqvist, M.; Hotokka, M.; Rasanen, M. Chem. Phys. 1998, 229, 137.

(49) Takeuchi, H.; Tasumi, M. Chem. Phys. 1983, 77, 21.

(50) Park, C. G.; Tasumi, M. J. Phys. Chem. 1991, 95, 2757.

(51) Muller, H. S. P.; Christen, D. J. Mol. Spectrosc. 2004, 228, 298.

(52) Reva, I.; Simão, A.; Fausto, R. Chem. Phys. Lett. 2005, 406, 126.

(53) Iogansen, A. V. Spectrochim. Acta, Part A 1999, 55, 1585.

(54) Rozenberg, M.; Shoham, G.; Reva, I.; Fausto, R. Spectrochim. Acta, Part A 2003, 59, 3253 .

(55) Rozenberg, M.; Loewenschuss, A.; Lutz, H.-D.; Marcus, Y. Carbohydr. Res. 1999, 315, 89.

(56) Rozenberg, M.; Iogansen, A. V.; Mashkovsky, A. A.; Odinokov, S. E. Spectrosc. Lett. 1972, 5, 75. 